DOI: https://doi.org/10.47405/mjssh.v6i7.837

\begin{tabular}{|c|c|}
\hline 4 & Malaysian Journal of Social Sciences and Humanities (MJSSH) \\
\hline $\begin{array}{l}\text { Malaysian Journa of } \\
\text { Social cciences and }\end{array}$ & Volume 6, Issue 7, July 2021 \\
\hline (MJ-sSH) & e-ISSN : 2504-8562 \\
\hline & $\begin{array}{l}\text { Journal home page: } \\
\text { www.msocialsciences.com }\end{array}$ \\
\hline
\end{tabular}

\title{
English Major Students' Perceptions of Using Animated Cartoons on English Vocabulary Knowledge of Rare Words in Malaysia
}

\author{
Muhammad Farriz Bin Aziz', Kamariah Bt Yunus' ${ }^{1}$, Nurul Fatihah Bt Mohamad Nazmi1 \\ ${ }^{1}$ Faculty of Languages and Communication, Universiti Sultan Zainal Abidin (UniSZA)
}

Correspondence: Muhammad Farriz Aziz (farrizaziz@yahoo.com)

\begin{abstract}
The rapid developments throughout language technologies have catered tremendous chances for learning and teaching vocabulary in second language learning. The development of vocabulary knowledge does not merely oscillate in academic vocabulary, high frequency vocabulary and technical vocabulary, English major students should also need to learn low-frequency vocabulary or rare vocabulary which enhance their language proficiency. In order to accommodate students with vocabulary knowledge of rare words, it should come with the best resort of teaching technique that can help them to learn in a meaningful way. One of the rarely used multimedia tools is animated cartoons. This paper aims at exploring the students' perceptions of using animated cartoons in improving their English vocabulary knowledge of rare words in Universiti Sultan Zainal Abidin (UniSZA), Terengganu. Employing a semi-structured interview, the qualitative data collection method was conducted. Employing the qualitative data collection method, semi-structured interviews were conducted to six students who learned vocabulary using animated cartoons to obtain their perceptions towards these multimedia materials in improving the English vocabulary knowledge of rare words. The results of semi-structured interviews highlighted the positive responses from the students who preferred animated cartoons as these materials in improving their English vocabulary knowledge of rare words. In conclusion, this study contributes to the current literature on English vocabulary learning of rare words by exposing and underlining the impacts of animated cartoons which provide opportunities for students to encounter a conducive technological-based learning environment.
\end{abstract}

Keywords: vocabulary knowledge, rare words, animated cartoons, English major students, semistructured interview

\section{Introduction}

In Malaysia, English was and is still a significant language of education, commerce and trade (Nasuruddin, 2016). English has been dominating as the language in the trade and industry sector in the country. Malaysia has accorded English as a second language status as stated in Article 152 and continues to be a compulsory subject taught at all level of education from primary to tertiary level. According to Hazita (2002, as cited in Azmi, 2013), the objective of English literacy in Malaysia covers the use of English in written and spoken forms, to understand various types of texts and to appreciate the aesthetic element of the language. She further suggests that all major races of Malaysia namely the Malays, Chinese and Indians, have accepted the importance of English literacy and its vastly positive influence on their future career. 
In relation to the language learning, it requires four main skills namely reading, writing, speaking, and listening in order to achieve a high proficiency level. Despite its prominence, the limited vocabulary knowledge will interrupt the learning process in mastering those skills as it "impedes student to express his/her idea" (Munir, 2016). Ketola (2019) further asserts that vocabulary knowledge plays a central role in language learning because it acts as the foundation in which language is used in reading, writing and communication. This is because, insufficient vocabulary in second language hinders an effective communication, and that provides reason for why vocabulary knowledge is often regarded as an important aspect for learning second language (Alqahtani, 2015). Thus, it shows the significance of vocabulary as the main component to master English language.

\section{Literature Review}

\section{An Overlook at English Vocabulary Learning at Tertiary Level for Malaysian students}

The concern over low literacy attainment in English language among Malaysian learners has been investigated quite extensively for over a few years. Lack of English proficiency specifically among university students is at alarming rate considering Malaysia is a country that use English as a second language in most fields. According to Sen (2011), an English lecturer with over 37 years of teaching experiences states that there has been a clear decline of English language proficiency over the past 20 years. She points out that the rot started when the medium of instruction was switched from English to Malay in the 1970s. Hence, this issue on students' lack of English proficiency should be put under the massive spotlight especially in tertiary level of education.

As far as English major students are concerned, Afzal (2019) identifies the problem faced by the students in pronouncing news words, spelling new words, proper usage of new words, identifying the grammatical form of words, guessing the definitions of context, and others. Consequently, he concluded these vocabulary learning difficulties undermine students' understanding of reading, writing, and communication skills due to inadequate of vocabulary, thus demotivating them to use English as much as possible. This is in parallel with the statement by Yunus, Mohamed, and Waelateh (2016) who indicate that for the improvement of literacy skills and communication in academic field, English major students must have vast vocabulary knowledge. To add salt to the wound, a study by Sudarman and Chinokul (2018) indicate that the English major students failed to master the 2,000 or 3,000 words of high frequency vocabulary level and academic vocabulary level. They further highlight the participants' low vocabulary proficiency in which "could be assumed due to lack of vocabulary knowledge" (Ivone, 2005).

Therefore, Aziz and Sulicha (2016) claimed that vocabulary should be learned first, since this important aspect connects students of four language skills. In addition, Vitasmoro and Chandra (2019) also asserted that when students have a lot of vocabulary, it can aid them to develop four language skills swiftly. Thus, it shows the importance of vocabulary which provides the fundamental aspect of students to learn the language. To elucidate, students with lack of vocabulary knowledge be likely to become loss of words in communicating English, facing no idea in writing essays, unable to understand new vocabularies while reading and having difficulties to comprehend the vocabularies during listening.

\section{Incorporating Animated Cartoons in English Vocabulary Learning}

In the effort of catering the problems encountered by the tertiary level of English major students, majority of the universities have been utilizing the chances of multimedia to improve and advance the traditional learning over the decade. The advent of sophisticated technologies in educational field for the past two decades have demanded the teachers to use multimedia as part of teaching tools. Ramezanali (2017) indicates that in order to learn new words and retain them longer, there are new instructional and context-based tools accessible to assist the students. The use of movies, songs, film, animated cartoons and other multimedia technology in teaching vocabulary have become the tools for the teachers to use these methods rather than sticking on using the traditional way of teaching. These 
multimedia technologies that are used in teaching vocabulary help in students' participations which eventually offer active learning environments for students and boosting up students' motivation.

One of the multimedia tools that can be employed in enhancing teaching and learning is animated cartoons. Using animated cartoons as the instructional materials can enhance students' motivation in learning English vocabulary rather than distributing paper-based materials, teaching using whiteboard and any other conventional methods that do not promote students' engagement towards the materials that are being presented to them during the lesson. A study by Eker and Karadeniz (2014) point out that there is no instrument that can cater teaching as exciting as cartoons. The studies on the impact of animated cartoons have revealed that animated cartoon can be utilized an alternative to teach English vocabulary instead of traditional teaching method. To buttress this claim, prior study by Becker et al., (2006) and O' Day (2007) find out that as an alternative or supplement to traditional teaching methods, the use of animated cartoons have been adopted by many educators.

Using animated cartoons as the instructional materials can enhance students' motivation in learning English vocabulary rather than distributing paper-based materials, teaching using whiteboard and any other conventional methods that do not promote students' engagement towards the materials that are being presented to them during the lesson. Prensky (2004) states that "traditional instruction methods lack the motivational incentives needed to keep today's students engaged in the instructional content". Additionally, teachers need to put more efforts into selecting appropriate materials and teaching method to produce a joyful and motivating learning environment (Su and Liang, 2014). One of the important components in learning English is vocabulary yet, the students especially in the digital age remark vocabulary learning is tedious for them. Hence, this paper is aimed to explore the students' perceptions of using animated cartoon in improving their English vocabulary knowledge specifically of rare words.

\section{Theoretical Framework}

This study applied the Cognitive Theory of Multimedia that was introduced by Mayer. Figure 1 shows on how memory works and responds to multimedia according Mayer's Cognitive Theory of Multimedia. The student must go through three main cognitive processes which are selecting, organizing and selecting to create a meaningful learning in multimedia environment according to Mayer (Pusadee, 2013).

Figure 1: Cognitive Theory of Multimedia Learning Model

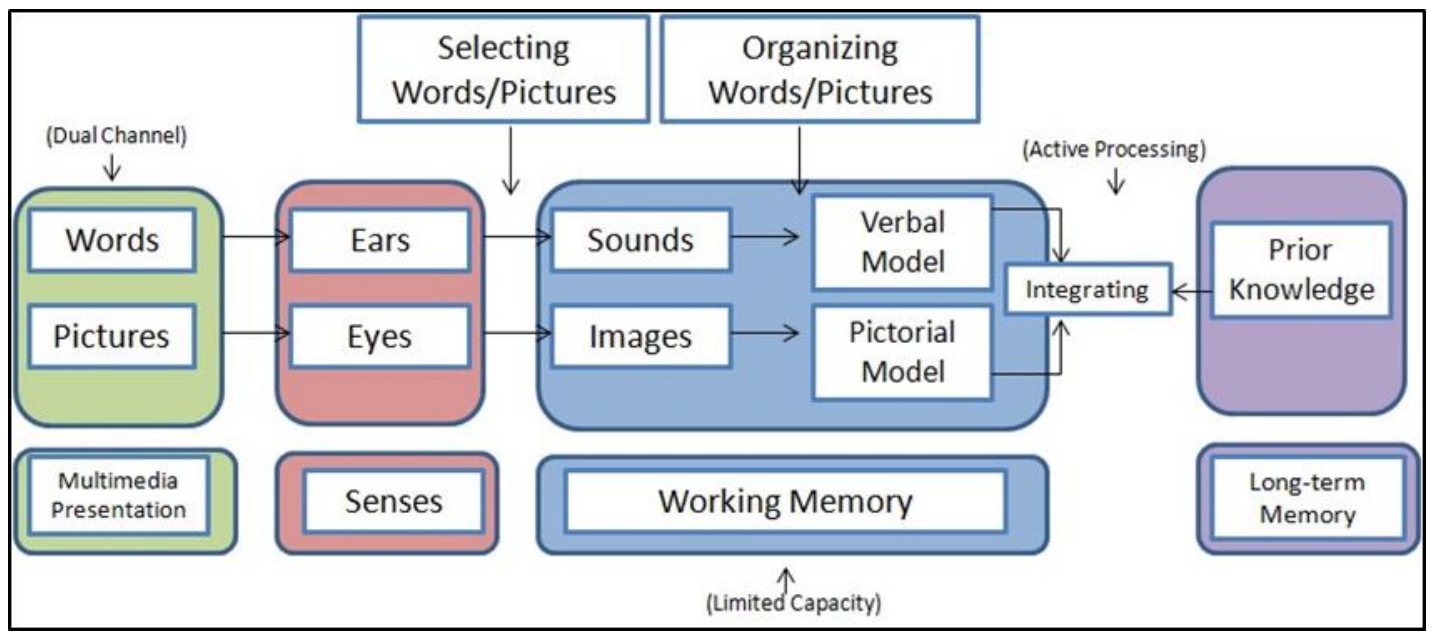

However, Mayer (2005) specifies these three cognitive processes into five cognitive processes: 1) selecting relevant words and processing into verbal working memory 2) selecting relevant images and processing into visual working memory 3 ) organizing selected words into verbal model 4) organizing selected images into pictorial model 5) integrating the verbal and pictorial representations with each other with prior knowledge. Figure 1 displays the process that refers on how students' cognitive system 
reacts to animated cartoons as the multimedia materials which are presented to them in learning English vocabulary.

According to Mayer (2005), he claims that there are five forms of representation in Cognitive Theory of Multimedia when the students are presented with multimedia materials. Each form will describe the process that will encounter by students' cognitive system in learning English vocabulary using animated cartoons. The first form of representation is the multimedia presentation. In this study, students watch animated cartoons in learning vocabulary which consist of words and pictures as the multimedia presentations. In animated cartoons, words involve spoken words (narrations) and written words (on-screen texts). On the other hand, the pictures consist of moving images (animation) of the characters. Next, the second form is sensory representation. In animated cartoons, the narrations are detected by ears while the animations are detected by eyes. The sensory representation in sensory memory consists of acoustic representation (sounds) and iconic representation (images). In this stage, the students' visual and auditory start to stimulate and responding to animated cartoons. To obtain a clear view on how animated cartoons work in vocabulary learning, Figure 2 and Figure 3 show the example of the animated cartoon of the vocabulary "Neophyte".

Figure 2: The definition, part of speech, definition, synonyms and antonyms of the words are narrated by the narrator

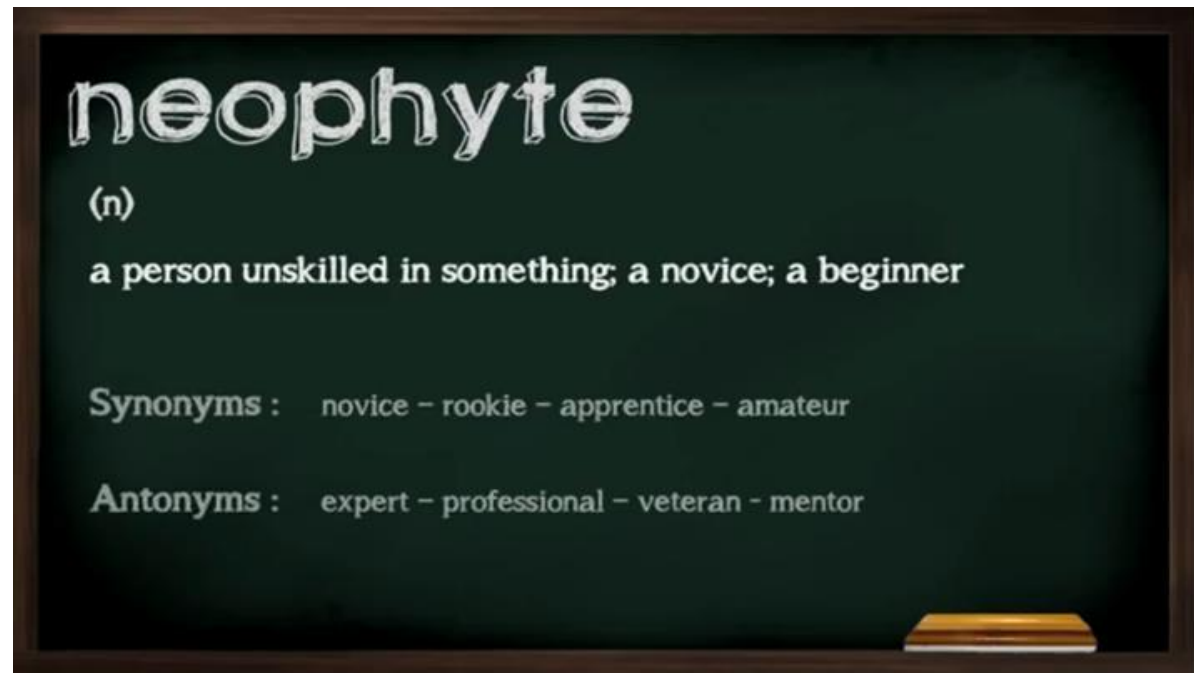

Figure 3: The scenes that describe on how to use the word "Neophyte".

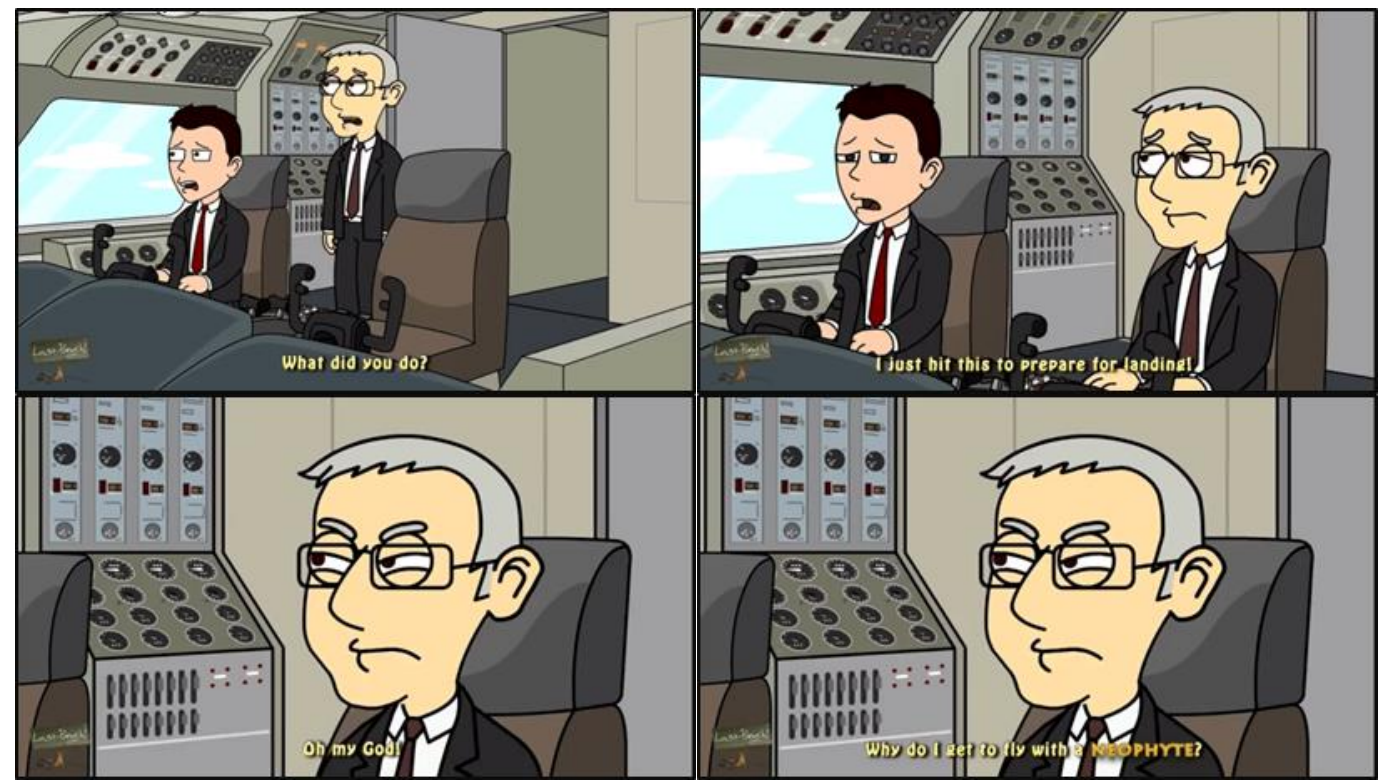


The third form is shallow working memory representation. The process of "selecting" occurs at this form. The students start to pay attention on the information of incoming sounds and images of animated cartoon materials that are presented to them. Then, the student will select some of relevant words from narration (as shown by the arrow from words to ears to sound) into verbal working memory. For example, according to animated cartoon segmentations from Figure 2 and Figure 3, the student will select the relevant words that will be represented in verbal working memory such as neophyte, unskilled person, captain, aeroplane and working with neophyte.

Meanwhile, the relevant images (as shown by the arrow from pictures to ears to sound) and on-screen texts (as shown by the arrow from words to ears to sound) are selected into visual working memory that are associated with English vocabulary learning. To illustrate, according to the Figure 3, the student may select the image of the captain, aeroplane and unskilled pilot. The other images such as the door, the chairs and clouds are deleted from memory. "The need for selecting only part of presented message occurs because of capacity limitations in each channel of the cognitive system" (Mayer, 2005, p.39). Then, the selected information will be transmitted to fourth form of representation for further processing.

The fourth form of representation is deep working memory representation. The process of "organizing" happens at this form. This process involves organizing selected words into coherent representation which is verbal model. The inputs for organizing selected words are from narrations and on-screen text (it occurs when the students mentally articulate the text). The selected words or phrases from animated cartoons are organized which involves constructing the simple structure. For example, the student can build a simple structure from selected verbal elements of vocabulary learning in animated cartoon: "first: Neophyte is unskilled person; second: in an aeroplane; third: Captain regrets working with a Neophyte.”

The students also have to organize selected images into coherent representation, pictorial model. The inputs of organizing selected images are the animations that have connection with vocabulary. The application of cognitive process is required to change from animations to pictorial model. For example, the students may create a connection between the selected images: The captain is scolding a new clumsy pilot.

Lastly, the fifth form is prior knowledge which is stored in long-term memory. This stage involves making coordination between representations of word-based and image-based. The verbal model and pictorial model that are separately structured are integrated to form a new knowledge which also involves the connections with prior knowledge. "The process reflects the epitome of sense making because learner must focus on the underlying structure of the visual and verbal representations" (Mayer, 2005, p.40).

For instance, the student must connect the information that they have constructed in the verbal model"first: Neophyte is unskilled person; second: in an aeroplane; third: Captain regrets of working with a Neophyte"- and in the pictorial model - The captain is scolding a new clumsy pilot. The prior knowledge in long-term memory is applied when the student remembers the scene that happens in the aeroplane that relates to the word "Neophyte."

Thus, it is relevant to use animated cartoons in learning English vocabulary. Duquette, Renie and Laurier (1998) claim that using variety multimedia contexts in teaching such as animated images and images attached with text improve speed and enhance the vocabulary retention. The combination of texts with animation, sound, pictures and video provides a significant impact in vocabulary (Chun \& Payne, 2004). Akbulut (2007) also points out that the integration of multimedia is more efficient in facilitating vocabulary learning. This tallies with Bonin, Gelin, and Bugaiska (2013) who claim that words are easily recognized and recalled when using animation rather than non-animation materials. In addition, Leong, Abidin, and Saibon (2019) also asserted that the application of the three multimedia principles of Mayer's (2001) Cognitive Theory of Multimedia Theory (CTML) has made it possible for individuals to learn vocabulary implicitly. 
In conclusion, Cognitive Theory of Multimedia Learning (CTML) that is related to this study are explained and discussed. Thus, this provides a vivid view of the framework on how animated cartoons as one of the multimedia tools can assist students to achieve meaningful way of vocabulary learning.

\section{Methodology}

This study utilized a method of qualitative data that is obtained through interview. The semi-structured interview was used in this study which asked for students' perceptions and feedbacks towards the use of animated cartoons in learning English vocabulary. The questions of the interview were intended to explain the phenomena that related to learning vocabulary using animated cartoons. The results of the semi-structured interview were transcribed, coded, and finally analyzed to meet the purpose of this study.

\section{Participants}

In selecting the relevant sample size of the interviewees, Morse (1994) suggests at least six participants while Creswell (1998) recommends 6 to 25 participants. To fulfil the suggestions provided by Morse (1994) and Creswell (198), six participants are selected for the interview. All six participants were English major students from the Faculty of Languages and Communication in Universiti Sultan Zainal Abidin (UniSZA) who learned rare words using animated cartoons.

\section{Procedures}

Semi-structured interview took place three days after the participants learning rare words using animated cartoons. Six students were chosen for semi-structured individual (one-to-one) interview. There were four open-ended themes that consisted of Attention (A), Relevance (R), Confidence (C) and Satisfaction (S). These themes and questions for this interview were adopted and adapted from the Instructional Materials Motivation Survey (IMMS) that was introduced by Keller (2001). This interview looked at students' insights which were:

i. Participants voiced out their perceptions and insights during the four weeks of using animated cartoons in learning English vocabulary in tertiary education according to the themes; Attention (A), Relevance (R), Confidence (C) and Satisfaction (S).

ii. Participants recommended some inputs for future improvements.

These themes were constructed in the semi-structured interview to obtain broader perspectives about students' views on the animated cartoons used. Patton (2002) states that the reasons semi-structured interviews were selected as "it provides the researcher with the possibility to probe deeper than initially intended with on the interview guide, providing additional interesting, situational and more complete data" (p.347). In this study, the interview was recorded, transcribed and coded. Then, it was analysed according to themes.

\section{Data Analysis}

The interview data were reviewed to ensure the statements provided by the students were accurate. Then, the interview data were analyzed manually according to the themes that were related to the findings of the quantitative section of this study. Thus, Thematic Analysis was employed in this study. "Thematic analysis is a method for identifying, analysing and reporting patterns (themes) within data" (Braun \& Clarke, 2006, p.79).

\section{Result}

Students found out that using animated cartoons in learning vocabulary was the impressive method as it helped them to widen their vocabulary knowledge with the emergence of audio and visual elements. 
Based on the interviews, using animated cartoons have enhanced students' Confidence, Attention and Satisfaction in learning vocabulary in which it was in line with their interest. The responses of some students implied that animated cartoons helped them to learn and retrieve their vocabulary knowledge of rare words better with the assistance of the visual scenes as well as the sound to help them remember the words for the future usage. The students viewed animated cartoons as a tool of learning that possess rich explanations such as definition, synonyms, antonyms, and sentence structures to be interesting, entertaining, informative as well as enjoyable experience of learning new rare words.

The presentation of animated cartoons provided a vivid benefit as a learning aid according to introduction of detailed vocabulary knowledge of rare words in a famous method that is favored by most students during the interviews. This is supported by the result of the interview conducted by Bakla (2019) that concludes animated cartoons appears to be more appealing than the PPTs, as the students speaks about learning interactions even more favorably than those in the control group. The interview session carried out by Maranzana (2018) also portrays the same feedback that shows the use of animated cartoons gained improvement in their vocabulary knowledge compared to control group.

Using animated cartoons in learning also proved to be improving students' long term memory as most of them could remember the scenes related to the rare words that they have learned in the class. To illustrate, the students remembered the word "Cacophonous" which meant inharmonious sound because it related to the scene of the flamingos in the marsh. In addition, the students also remembered the scene that related to the rare word "Abate" as it included the situation in a clinic between the nurse and hunky patient who got afraid by the huge syringe. The scenes in animated cartoons assisted the students to build their confidence in learning vocabulary and accompanied with funny characters' voices as well as actions. The higher confidence level has encouraged students to feel comfortable in improving their vocabulary knowledge of rare words using animated cartoons. To add, Karakas and Saricoban (2012) highlight that the improvement of students from pre-test to post-test was accredited to the presentation of word in animated cartoons which made it more contextualized and ample for students to stimulate the definition of the words. These materials helped them to build their confidence level since learning the words that are not frequently used can be intimidating to them.

The findings of the semi-structured interviews also highlighted that animated cartoons drew student's attention in learning vocabulary. There are many features in animated cartoons that grab students' attention for instance colours, the characters' voices, the rare word itself, animation, sound, and numerous others. One reason that deserves the spotlight here during the semi-structured interview sessions was the students' learning preferences in enhancing their vocabulary knowledge of rare words. The visual style of learner would be attracted to watch the animated cartoons and their eye movements would stick to these materials which aided them to focus on the vocabulary presented to them. The embodiment of colours, written-text on the screen, animation, and images strengthened students' comprehension in learning and garnering the vocabulary knowledge of rare word inputs exposed in animated cartoons.

Meanwhile, the auditory learner would find animated cartoons as their main attraction in learning vocabulary because they do not prefer to read dictionaries and any printed materials. Instead, the pronouncers and the actors' voices attracted them to put emphasize on the rare words as they can listen to the explanations given attentively. Iftanti (2015) indicates that the concerted teaching technique, strategies, and skills of an English lecturer which are tailored to the students' learning styles make him/her truly inspirational as he/she eventually promotes the change in the process. Thus, using animated cartoons encourage students to lay their attention on the contents presented according to their most impactful style of learning.

\section{Discussion}

Based on the results obtained from the semi-structured interviews, it could be discussed that it was easier for students to read information on the screen through the exposure of animated cartoons rather than paper-based materials. As the students were always lazy to go through every page of dictionary 
just to find the meaning of the words, animated cartoons were relevant to be employed as the materials for vocabulary learning because it was the easiest way to understand the rare words and how it could be applied in the contextual situation. "Cartoons represent an attempt to ask some of the questions that students might like to ask, if they would think in terms of everyday life situations/ideas, and actually get some answers" (Kose, 2013, p.10).

As a matter of relevant theme was taken into consideration, it could be stated that animated cartoons were feasible to be employed for vocabulary learning as these materials helped the students to create the links between their existing knowledge and the new vocabulary knowledge of rare words with the related scenes which enhanced their memorization of the rare words learned. A student who learned vocabulary through paper-based materials had to interpret the information thoroughly and to connect the words with his/her life situation and experience that was related with the word context. Animated cartoon is a brilliant and uplifting complement to instruction because of the combination of the students' familiarity and recognition together with attentive pedagogical integration (Dalacosta et al., 2011).

Meanwhile, students who learned using animated cartoons received the subtle and total information from the depiction of these materials, thus they did not have to craft their own understanding which might deviate from the real meaning of the rare words. By creating impactful learning environment, students could feel the sense of satisfaction towards the learning materials presented to them. Animated cartoons could increase students' satisfaction in learning vocabulary which acted as a self-driving force for them to achieve the learning goals and to pass in the post-test. This element was related to students' cognitive processing where at first, they felt contented with animated cartoon materials used in learning vocabulary and followed by building up their goals to know more about the rare words indirectly. "Cognitive process in the learners' mind which is cause of thinking and rethinking about the new words help the learners to store the words in their long-term memory" (Shahpari, Shamshiri, \& Rashidi, 2014, p.2).

The element of satisfaction also existed when the students could accomplish their tasks using animated cartoons materials as well as answering the vocabulary questions correctly with the assistance of animated cartoons. In addition, when the students knew the rare words they have learned using animated cartoons and could answer the questions pertaining to rare words very well during the posttest, the students felt that they have reached the feeling of accomplishment in the learning opportunity.

\section{Implications}

The study is also vital, as it has highlighted four main implications to animated cartoons and students' vocabulary knowledge of rare words. First, the domination of animated cartoon materials over paper based materials (traditional method) towards students' vocabulary knowledge of rare words. Second, animated cartoons could be considered as one of the most exciting and preferable vocabulary learning methods. Third, this study has triggered an utmost wake-up call to English major students on how scarce their vocabulary knowledge is when they did not know most of the rare words introduced to them during the treatments. Lastly, the existence of numerous attractive features in animated cartoons such as audio/sound, visual/image, animation and colours help to improve students' vocabulary learning.

\section{Conclusion}

The findings of the semi-structured interviews indicated that students preferred learning vocabulary using animated cartoons compared to using traditional methods alone in aiding the acquisition of rare words, improvement of comprehension on how to use these rare words in the right context and helping to store these rare words in their short and long-term memory. With the existence of special elements in animated cartoons such as visual, colours, sound and animation has created interesting vocabulary learning lessons and attracted their attention towards the materials. In addition, the method was 
efficacious in boosting their confidence level as the animated cartoons were rich in contents that provided the easiest ways for the students to understand the rare words through animation. To summarize, the use of animated cartoons in learning vocabulary of rare words is sophisticatedly welldesigned to provide better comprehension of the lesson and to advance traditional learning such as using paper based materials. It proved to be one of the effective learning methods using multimedia at tertiary level for English major students.

\section{References}

Afzal, N. (2019). A Study on Vocabulary-Learning Problems Encountered by BA English Majors at the University Level of Education. Arab World English Journal, 10(3), 81-98. doi: 10.24093/awej/vol10no3.6.

Akbulut, Y. (2007). Effects of multimedia annotations on incidental vocabulary and reading comprehension of advanced learners of English as a foreign language. Instructional Science, 35, 499-517.

Alqahtani, M. (2015). The Importance of Vocabulary in Language Learning and How to be taught. International Journal of Teaching and Education, 3(3), 21-34. doi:10.20472/TE.2015.3.3.002.

Aziz, Z. A. \& Sulicha, R. (2016). The Use of Cartoon Films as Audio-Visual Aids to Teach English Vocabulary. English Education Journal (EEJ), 7(2), 141-154.

Azmi, M. N. L. (2013). National Language Policy and Its Impacts on Second Language Reading Culture. Journal of International Education and Leadership, 3(1). https://files.eric.ed.gov/fulltext/EJ1136083.pdf

Becker, W. E., Watts, M., \& Becker, S. (2006). Teaching Economics: More Alternatives to Chalk and Talk. Northampton, MA: Edward Elgar.

Bonin, P., Gelin, M., \& Bugaiska, A. (2013). Animates are better remembered than inanimate: further evidence from word and picture stimuli. Springer, 1-13. doi:10.3758/s13421-013-0368-8.

Braun, V., \& Clarke, V. (2006). Using thematic analysis in psychology Using thematic analysis in psychology. Qualitative Research in Psychology, 3(2), 77-101. doi: 10.1191/1478088706qp063oa.

Creswell, J. W. (1998). Qualitative Inquiry Research Design: Choosing among five traditions. Thousand Oaks, CA: Sage.

Dalacosta, K., Kamariotaki-paparrigopoulou, M., Palyvos, J. A., \& Spyrellis, N. (2009). Computers \& Education Multimedia application with animated cartoons for teaching science in elementary education. Computers \& Education, 52(4), 741-748. doi:10.1016/j.compedu.2008.11.018.

Duquette, L., Renie, D., \& Laurier, M. (1998). The evaluation of vocabulary acquisition when learning French as a second language in a multimedia environment. Computer Assisted Language Learning, 11(1), 3-34.

Eker, C., \& Karadeniz, O. (2014). The Effects of Educational Practice with Cartoons on Learning Outcomes. International Journal of Humanities and Social Sciences, 4(14), 223-234.

Iftanti, E. (2015). Investigating Inspiring English Lecturers in a Faith-Based Educational Institution: EFL Learners' Perception. Dinamika Ilmu, 15(2), 343-358.

Ivone, F. M. (2005). Teaching English as a foreign language in Indonesia: The urge to improve classroom vocabulary instruction. TEFLIN Journal, 16(2), 195-208.

Karakas, A., \& Saricoban, A. (2012). The Impact of Watching Subtitled Animated Cartoons on Incidental Vocabulary Learning of ELT Students. Teaching English with Technology, 12(4), 315.

Kose, E. O. (2013). Effects of Cartoons on Students' Achievement and Attitudes in Biology Teaching (Endocrine System). Kastamonu Education Journal, 21(3), 931-941.

Leong, A. C. H., Abidin, M. J. Z., \& Saibon, J. (2019). Learners' Perceptions of the Impact of Using Digital Storytelling on Vocabulary Learning. Teaching English with Technology, 19(4), 3-26.

Maranzana, S. (2018). Animated Cartoons in the Language Classroom: Attitudes and Perceptions of Italian L2 Students (Unpublished doctoral dissertation). The University of Arizona. Retrieved from: http://hdl.handle.net/10150/631460.

Mayer, R. E. (2005). Cognitive Theory of Multimedia learning. In R.E. Mayer (Ed). The Cambridge Handbook of Multimedia Learning. New York: Cambridge University Press. 
Munir, F. (2016). The Effectiveness of Teaching Vocabulary by Using Cartoon Film toward Vocabulary of EFL Students. Journal of English Language Teaching and Linguistics, 1(1), 1337. doi: 10.21462/jeltl.v1i1.20.

Morse, J. M. (1994). Designing Funded Qualitative Research. In Denizin, N. K., \& Lincoln, Y. S., Handbook of Qualitative Research (2nd ed.). Thousand Oaks, CA: Sage.

Nasaruddin, N. S. A. (2018). How Malaysian Primary ESL Learners Build Vocabulary Using Multimedia Technology (Unpublished Master's Thesis). International Islamic UniversityMalaysia.

O' Day, D. H. (2007). The Value of Animations in Biology Teaching: A Study of Short-Term and Long Term Memory Retention. CBE: Life Sciences Education, 5, 155-163.

Sen, T. E. (2011, June 9). Poor English skills: 'Rot started in the 70s'. Free Today. Retrieved April 4, 2017, from: http://www.freemalaysiatoday.com/category/nation/2011/06/09/poor-englishskills-ot-started-in-the-70s/.

Shahpari, N., \& Shamshiri, H. R., \& Rashidi, N. (2014). Intentional vs. Incidental vocabulary learning \& Iranian EFL Learners Retention. Enjoy Teaching Journal, 2(3), 1-11.

Sudarman, S., \& Chinokul, S. (2018). The English Vocabulary Size and Level of English Department Students at Kutai Kartanegara University. English, Teaching, Learning, and Research Journal, 4(1), 1-16. doi: 10.24252/Eternal.V41.2018.A1

Patton, M. Q. (2002). Qualitative research and evaluation methods (3rd ed.). Thousand Oaks, CA: Sage.

Yunus, K., Mohamed, M., \& Waelateh, B. (2016). The Breadth of Receptive Vocabulary Knowledge among English Major Students. Journal of Nusantara Studies (JONUS), 1(1), 7-17. 